\title{
Low-carbohydrate diets and cardiovascular and total mortality in Japanese: a 29-year follow-up of NIPPON DATA80
}

\author{
Yasuyuki Nakamura ${ }^{1,2 *}$, Nagako Okuda ${ }^{3}$, Tomonori Okamura ${ }^{4}$, Aya Kadota ${ }^{2}$, Naoko Miyagawa $^{2}$, \\ Takehito Hayakawa ${ }^{5}$, Yoshikuni Kita ${ }^{6}$, Akira Fujiyoshi ${ }^{2}$, Masato Nagai ${ }^{2}$, Naoyuki Takashima ${ }^{2}$, \\ Takayoshi Ohkubo $^{7}$, Katsuyuki Miura ${ }^{2,8}$, Akira Okayama9 and Hirotsugu Ueshima ${ }^{2,8}$ for the \\ NIPPON DATA Research Group \\ ${ }^{1}$ Cardiovascular Epidemiology, Kyoto Women's University, 35 Imakumano Kitahiyoshi-cho, Higashiyama-ku, \\ Kyoto 605-8501, Japan \\ ${ }^{2}$ Department of Health Science, Shiga University of Medical Science, Otsu, Japan \\ ${ }^{3}$ Department of Health and Nutrition, University of Human Arts and Sciences, Saitama, Japan \\ ${ }^{4}$ Department of Preventive Medicine and Public Health, School of Medicine, Keio University, Tokyo, Japan \\ ${ }^{5}$ Department of Hygiene and Preventive Medicine, Fukushima Medical University, Fukushima, Japan \\ ${ }^{6}$ Tsuruga City University of Nursing, Tsuruga, Japan \\ ${ }^{7}$ Department of Hygiene and Public Health, Teikyo University School of Medicine, Tokyo, Japan \\ ${ }^{8}$ Center for Epidemiologic Research in Asia, Shiga University of Medical Science, Otsu, Japan \\ ${ }^{9}$ Research Center for Lifestyle-Related Diseases, Tokyo, Japan
}

(Submitted 1 February 2014 - Final revision received 1 June 2014 - Accepted 5 June 2014 - First published online 7 August 2014)

\begin{abstract}
Long-term safety of consuming low-carbohydrate diets (LCD) in Asian populations, whose carbohydrate intake is relatively high, is not known. In the present study, the association of LCD with CVD and total mortality was assessed using data obtained in the NIPPON DATA80 (National Integrated Project for Prospective Observation of Non-communicable Disease and Its Trends in the Aged 1980) during 29 years of follow-up. At baseline in 1980, data were collected from study participants aged $\geq 30$ years from randomly selected areas in Japan. LCD scores were calculated based on the percentage of energy as carbohydrate, fat and protein, estimated by $3 \mathrm{~d}$ weighed food records. A total of 9200 participants (56\% women, mean age 51 years) were followed up. During the follow-up, 1171 CVD deaths ( $52 \%$ in women) and 3443 total deaths ( $48 \%$ in women) occurred. The multivariable-adjusted hazard ratio (HR) for CVD mortality using the Cox model comparing the highest $v$. lowest deciles of LCD score was 0.60 (95\% CI 0.38, 0.94; $\left.P_{\text {trend }}=0 \cdot 021\right)$ for women and 0.78 (95\% CI $\left.0.58,1.05 ; P_{\text {trend }}=0.079\right)$ for women and men combined; the HR for total mortality was 0.74 (95\% CI 0.57 , 0.95 ; $\left.P_{\text {trend }}=0.029\right)$ for women and $0.87\left(95 \%\right.$ CI $\left.0.74,1.02 ; P_{\text {trend }}=0.090\right)$ for women and men combined. None of the associations was statistically significant in men. No differential effects of animal-based and plant-fish-based LCD were observed. In conclusions, moderate diets lower in carbohydrate and higher in protein and fat are significantly inversely associated with CVD and total mortality in women.
\end{abstract}

Key words: Low-carbohydrate diets: Cardiovascular mortality: Total mortality: Cohort studies

Overweight and obesity are the fifth leading causes of death globally $^{(1)}$. The effectiveness of diets low in carbohydrate and high in protein and fat to promote weight loss and reduce cardiometabolic risk has been shown in several systematic review and meta-analysis studies ${ }^{(2-5)}$. However, the safety of consuming low-carbohydrate diets (LCD) remains controversial. Although some recent cohort studies have supported the long-term beneficial effects of plant-based LCD on cardiovascular morbidity or mortality ${ }^{(6)}$, other studies have suggested that LCD may increase the risk of CVD morbidity and mortality ${ }^{(7-10)}$. Differential effects of animal-based and plantbased LCD on health outcomes have also been indicated ${ }^{(6,7,11)}$.

Very recently, a meta-analysis of observational studies on the association of LCD with total mortality has been carried

Abbreviations: BP, blood pressure; HR, hazard ratios; ICD, International Classification of Disease; LCD, low-carbohydrate diets; NIPPON DATA, National Integrated Project for Prospective Observation of Non-communicable Disease and Its Trends in the Aged; NNSJ, National Nutritional Survey in Japan; SES, socio-economic status. 
out by Noto et al. ${ }^{(12)}$. This study showed LCD to be associated with a significantly higher risk of total mortality without any changes in CVD mortality and incidence. Surprisingly, however, these authors analysed data of individuals mostly living in European countries or in the USA; no data of those living in Japan were analysed. Compared with Western populations, Japanese people living in Japan consume a higher amount of carbohydrate and a lower amount of saturated fat. Fish intake in Japan is very high compared with that in Western countries ${ }^{(13-16)}$. Thus, it is quite possible that LCD may have very different effects on health outcomes in Japanese people living in Japan.

The aim of the present study was to assess the association of usual, animal-based, and plant-fish-based LCD with CVD and total mortality in a large cohort of participants randomly recruited from selected districts in Japan.

\section{Participants and methods}

\section{Participants}

Cohort studies of the National Survey on Circulatory Disorders, Japan, are known as NIPPON DATA (National Integrated Project for Prospective Observation of Noncommunicable Disease and Its Trends in the Aged). The present study analysed data obtained from NIPPON DATA80, in which baseline surveys were carried out in 1980. Details of this cohort have been reported elsewhere ${ }^{(17)}$.

A total of 300 districts were randomly selected throughout Japan. The selection process is outlined below. For a comprehensive survey of living conditions, 1800 residential areas were sampled from over 900 thousand Population Census areas of the year 1975 by stratified sampling. Each area was divided into two districts. From 3600 districts, 300 were chosen by stratified sampling for the present study. A total of 13771 individuals aged $\geq 30$ years resided in the participating districts. All of them were invited to participate in the study. Of them, 10546 community-based individuals agreed to participate in the study. The participation rate was $76.6 \%$ (10546 of 13771) before exclusion for reasons mentioned below. The survey consisted of history-taking, physical examinations, blood tests and a self-administered questionnaire on lifestyle. For the present study, the participants were followed up to 2009 (NIPPON DATA80, 1980-2009).

The participants were excluded from follow-up because of missing baseline data ( $n$ 84), a past history of CHD or stroke at baseline ( $n$ 153), or loss to follow-up ( $n$ 1109). The latter group was excluded because of the absence of a permanent address that was needed to link to vital statistical records. The final sample comprised 9200 participants (5160 (56\%) women and $4040 \mathrm{men})$. There were no significant differences between participants who were lost to follow-up and those who were included in the present study in terms of several risk factors.

\section{Biochemical and baseline examinations}

The baseline surveys were conducted at public health centres according to a standardised manual. Blood pressure (BP) was measured by trained research nurses using a standard mercury sphygmomanometer by attaching it to the right arm of seated participants after at least $5 \mathrm{~min}$ of rest. Hypertension was defined as systolic BP $\geq 140 \mathrm{mmHg}$ or diastolic BP $\geq 90 \mathrm{mmHg}$ or use of antihypertensive agents. Height and weight were measured in stocking feet and light clothing. BMI was calculated as weight $(\mathrm{kg})$ divided by the square of height $\left(\mathrm{m}^{2}\right)$.

A lifestyle survey was also carried out using a selfadministered questionnaire. The participants were also asked about their employee class (executive, professional and others (including homemaker)). Reported information was confirmed by public health nurses through face-to-face interviews.

Casual blood samples were drawn and centrifuged within $60 \mathrm{~min}$ of collection and stored at $-70^{\circ} \mathrm{C}$ until analyses as described previously ${ }^{(17,18)}$. Serum concentrations of glucose were measured using the cupric-neocuproine method, and the value was converted so as to better correspond with those obtained from the more widely used hexokinase $\operatorname{method}^{(19)}$.

\section{Nutritional survey}

We used the data of the National Nutritional Survey in Japan (NNSJ). In the NNSJ, a food intake survey using weighed food records over three consecutive representative weekdays was conducted by specially trained dietary interviewers. Dietary interviewers visited participants at their homes at least once during the survey. We used the Standard Tables for Food Composition in Japan, 4th edition, with matched fatty acid and micronutrient intake values to calculate Japanese nutrient intake values. We estimated the nutrient intake of each household member by dividing household intake data of the NNSJ80 conducted in 1980 proportionally using average intakes by sex and age groups calculated for the NNSJ conducted in 1995, when collection of information on dietary intakes of individual household members started. These methods have been described in detail elsewhere ${ }^{(20)}$. For each individual, means of the estimated intake of individual nutrients from the $3 \mathrm{~d}$ records were used in the analyses. The validation of this method was ascertained in a previous study ${ }^{(21)}$. Although alcohol intake is an important dietary factor, it was not included in the integrated datasets. Intakes of alcoholic beverages were recorded in the NNSJ, and the alcohol intake per household was included in the NNSJ datasets. However, we thought that calculation of the alcohol intake of individuals from the intake per household would not be appropriate for the investigation of the alcohol-disease association, due to the large inter-individual differences in alcohol consumption within a household ${ }^{(20)}$. Therefore, we used the values of alcohol consumption frequency recorded in NIPPON DATA. We present data as the contribution to total energy intake $(\% \mathrm{~kJ})$ from carbohydrate, total fat, SFA, MUFA+PUFA, total protein, and vegetable protein; green and yellow vegetables, fruits, fish, meats, and eggs $(\mathrm{g} / \mathrm{d})$; total dietary fibre $(\mathrm{g} / 4186 \mathrm{~kJ}(1000 \mathrm{kcal}))$; and $\mathrm{Na}$ and $\mathrm{K}$ (mg/4186 kJ (1000 kcal)). 


\section{Calculation of the low-carbohydrate diet score}

The LCD score was calculated by modifying the methods of Halton et $a l^{(6)}$. Instead of calculating scores based on animal or vegetable fat, we used more specifically SFA or MUFA+PUFA values, because the harmful effects of SFA and the beneficial effects of MUFA+PUFA are known. Data are reported as a percentage of energy. Women and men were analysed separately, by dividing them into eleven strata each for fat, protein and carbohydrate intake. For fat and protein, the points ranged from 10 , given to participants in the highest stratum, to 0, given to participants in the lowest stratum. For carbohydrate, the order of the strata was reversed. The points for each of the three macronutrients were then summed to obtain the overall diet score, which ranged from 0 to 30. Herein, this score is called the usual LCD score. Because previous studies have shown differential effects of animal-based and plant-based LCD on health outcomes, we also created two additional LCD scores. One was calculated according to the percentage of energy as carbohydrate, animal protein and SFA and the other according to the percentage of energy as carbohydrate, vegetable protein and MUFA+PUFA. Herein, the former is called the animal-based LCD score and the latter is called the plant-fish-based LCD score.

\section{Endpoint determination}

To determine the cause of death after 29 years of follow-up, we used the National Vital Statistics Database of Japan with permission from the Management and Coordination Agency, Government of Japan. The underlying causes of death were coded according to the 9th International Classification of Disease (ICD-9) through the end of 1994 and ICD-10 from the beginning of 1995 . The details of the classification used in the present study have been described elsewhere ${ }^{(22)}$. The causes of CVD deaths (ICD-9: 390-459 and ICD-10: I00-I99) were identified. Approval for the study was obtained from the Institutional Review Board of Shiga University of Medical Science (no. 12-18, 2000).

\section{Statistical analyses}

SAS version 9.4 for Windows (SAS Institute, Inc.) was used for the analyses. We divided the participants into ten deciles according to their LCD score. Age data are reported as means and standard deviations. For other continuous variables, we obtained age-adjusted data by ANCOVA, and these data are reported as means with their standard errors. Prevalence is reported as a percentage. Variables were compared across the ten deciles according to the LCD score. The $\chi^{2}$ test was used to compare dichotomous variables, and when statistically significant, followed by a post hoc logistic analysis adjusted for age, taking decile 1 as a reference. A one-way ANOVA was used to compare means among the groups, and when significant, followed by a post hoc Dunnett's test, taking decile 1 as a reference.
To assess the association between the LCD score and CVD and total mortality, multivariable-adjusted hazard ratios (HR) and $P$ values were calculated using a Cox proportionalhazards model. Women and men were analysed separately and combined. Variables in model 1 were age and deciles of diet scores. Model 2 comprised model 1 variables and BMI (five categories divided at $18.5,23,25$ and $30 \mathrm{~kg} / \mathrm{m}^{2}$; $18.5-23 \mathrm{~kg} / \mathrm{m}^{2}$ : a reference), hypertension, cigarette smoking (never-smokers, ex-smokers, and three categories of current smokers divided at twenty and forty cigarettes per d; neversmokers: a reference), and alcohol drinking (ex-drinkers, current drinkers and never-drinkers; never-drinkers: a reference). Model 3 comprised model 2 variables and serum total cholesterol and blood glucose concentrations (standardised to have the mean at 0 (SD 1)) and serum creatinine concentrations (divided at the 75 th percentile, $10 \mathrm{mg} / \mathrm{l}$ ). Model 4 comprised model 3 variables and total dietary fibre intake, Na:K ratio and employee classes (executive, professional and others; others: a reference). Model 3 and 4 in women and men combined comprised model 3 and 4 variables and sex. To determine whether the food records obtained in 1980 were representative of diet in the subsequent 29 years, model 4 analyses of usual LCD score for CVD mortality in women at 14 and 19 years of follow-up were carried out. All the variables in model 4 were retained using the PROC GLMSELECT option with the LASSO selection method. Thus, collinearity was not a problem in the analysis.

\section{Results}

\section{Descriptive statistics}

During follow-up for 29 years (224610 person-years), 1171 CVD deaths ( $52 \%$ in women) and 3443 total deaths (48\% in women) were confirmed.

Criteria for determining the LCD score for women are given in Table 1 and those for men are given in Table S2 (available online). In both women and men, about $60 \%$ of energy was from carbohydrate, about $15 \%$ was from protein and about $20 \%$ was from fat. For female participants in the lowest stratum of carbohydrate intake, the intake values ranged from $17 \cdot 3$ to $53.5 \%$, and for male participants, the values ranged from 18.8 to $51.6 \%$. For female participants in the highest stratum of carbohydrate intake, the intake values ranged from 71.3 to $83.3 \%$, and for male participants, the values ranged from $68 \cdot 3$ to $81 \cdot 0 \%$.

The characteristics of participants in 1980 according to the LCD score for women are given in Table 2. The mean intakes of rice, fish and shellfish, and meats were about 200, 100 and $50 \mathrm{~g} / \mathrm{d}$, respectively. For women in the higher-LCD score groups of all the three LCD scores, mean age was lower, age-adjusted rice intake was lower; age-adjusted intakes of fruits, vegetables, fish and shellfish, meats, and eggs were higher; and the prevalence of professional employee class was higher. For women in the higher-LCD score groups of two of the LCD scores, except the animal-based LCD score, age-adjusted total fibre, $\mathrm{Na}$ and $\mathrm{K}$ intakes were higher. Women in the higher-animal-based LCD score groups 
Table 1. Category limits for nutrients used in the determination of the low-carbohydrate diet (LCD) score for women*

\begin{tabular}{|c|c|c|c|c|c|c|c|}
\hline Points & $\begin{array}{l}\text { Carbohydrate } \\
\text { (\% of energy) }\end{array}$ & $\begin{array}{l}\text { Total protein } \\
\text { (\% of energy) }\end{array}$ & $\begin{array}{c}\text { Total fat } \\
\text { (\% of energy) }\end{array}$ & $\begin{array}{l}\text { Animal protein } \\
\text { (\% of energy) }\end{array}$ & $\begin{array}{c}\text { SFA } \\
\text { (\% of energy) }\end{array}$ & $\begin{array}{l}\text { Vegetable protein } \\
\text { (\% of energy) }\end{array}$ & $\begin{array}{l}\text { MUFA+PUFA } \\
\text { (\% of energy) }\end{array}$ \\
\hline 0 & $71 \cdot 3-83 \cdot 3$ & $9 \cdot 0-12 \cdot 9$ & $5 \cdot 4-14 \cdot 1$ & $1 \cdot 0-5 \cdot 8$ & $1.7-4.1$ & $1 \cdot 5-6 \cdot 2$ & $4.1-9.4$ \\
\hline 1 & $68 \cdot 4-71 \cdot 2$ & $13 \cdot 0-13 \cdot 6$ & $14 \cdot 2-16 \cdot 3$ & $5 \cdot 9-6 \cdot 6$ & $4 \cdot 1-4 \cdot 6$ & $6 \cdot 3-6 \cdot 6$ & $9.4-10 \cdot 6$ \\
\hline 2 & $66 \cdot 4-68 \cdot 3$ & $13 \cdot 7-14 \cdot 1$ & $16 \cdot 4-17 \cdot 8$ & $6 \cdot 7-7 \cdot 3$ & $4 \cdot 6-5 \cdot 0$ & $6 \cdot 7-6 \cdot 9$ & $10 \cdot 6-11.5$ \\
\hline 3 & $64 \cdot 7-66 \cdot 3$ & $14 \cdot 2-14.5$ & $17 \cdot 9-19 \cdot 2$ & $7.4-7.8$ & $5 \cdot 0-5 \cdot 4$ & $7 \cdot 0-7 \cdot 1$ & $11 \cdot 5-12 \cdot 3$ \\
\hline 4 & $63 \cdot 2-64 \cdot 6$ & $14.6-14.9$ & $19 \cdot 3-20 \cdot 4$ & $7 \cdot 9-8 \cdot 3$ & $5 \cdot 4-5 \cdot 8$ & $7 \cdot 2-7 \cdot 3$ & $12 \cdot 3-13 \cdot 1$ \\
\hline 5 & $61 \cdot 8-63 \cdot 1$ & $15 \cdot 0-15 \cdot 4$ & $20.5-21.9$ & $8 \cdot 4-8 \cdot 8$ & $5 \cdot 8-6 \cdot 2$ & $7.4-7.5$ & $13 \cdot 1-13 \cdot 9$ \\
\hline 6 & $60 \cdot 3-61 \cdot 7$ & $15 \cdot 5-15 \cdot 9$ & $22 \cdot 0-23 \cdot 1$ & $8.9-9.4$ & $6 \cdot 2-6 \cdot 6$ & $7 \cdot 6-7 \cdot 7$ & $13.9-14.8$ \\
\hline 7 & $58 \cdot 6-60 \cdot 2$ & $16 \cdot 0-16 \cdot 4$ & $23 \cdot 2-24 \cdot 7$ & $9.5-10.0$ & $6.6-7.0$ & $7 \cdot 8-8 \cdot 0$ & $14 \cdot 8-15 \cdot 7$ \\
\hline 8 & $56 \cdot 6-58 \cdot 5$ & $16 \cdot 5-17 \cdot 2$ & $24 \cdot 8-26 \cdot 5$ & $10 \cdot 1-10 \cdot 7$ & $7 \cdot 0-7.5$ & $8 \cdot 1-8 \cdot 3$ & $15 \cdot 7-16 \cdot 8$ \\
\hline 9 & $53 \cdot 6-56 \cdot 5$ & $17 \cdot 3-18 \cdot 3$ & $26 \cdot 6-28 \cdot 9$ & $10.8-11.9$ & $7.5-8.3$ & $8 \cdot 4-8.8$ & $16 \cdot 8-18 \cdot 4$ \\
\hline 10 & $17 \cdot 3-53 \cdot 5$ & $18 \cdot 4-32 \cdot 2$ & $29 \cdot 0-64 \cdot 0$ & $12 \cdot 0-33 \cdot 3$ & $8 \cdot 3-21 \cdot 4$ & $8 \cdot 9-14 \cdot 3$ & $18 \cdot 4-34 \cdot 4$ \\
\hline
\end{tabular}

* The LCD score for women was calculated by modifying the methods of Halton et al. ${ }^{(6)}$. We divided the study participants into eleven strata each for fat, protein and carbohydrate intake, expressed as a percentage of energy. For fat and protein, the points ranged from 10 , given to participants in the highest stratum, to 0 , given to those in the lowest stratum. For carbohydrate, the order of the strata was reversed. The points for each of the three macronutrients were then summed to obtain the overall diet score, which ranged from 0 to 30 (usual LCD score). We also created two additional LCD scores. One score was calculated according to the percentage of energy as carbohydrate, the percentage of energy as animal protein, and the percentage of energy as SFA (animal-based LCD score) and the other score according to the percentage of energy as carbohydrate, the percentage of energy as vegetable protein, and the percentage of energy as MUFA+PUFA (plant-fish-based LCD score).

consumed a higher amount of age-adjusted K. The intakes of flour products were higher in the higher-LCD score groups. Age-adjusted mean serum total cholesterol concentrations were significantly higher in the higher-LCD score groups. There were no differences in mean BMI, blood glucose concentrations and total energy intake among the groups.

The characteristics of participants in 1980 according to the LCD score for men are given in Table S3 (available online). The mean intakes of rice, fish and shellfish, and meats were about 300, 120 and $65 \mathrm{~g} / \mathrm{d}$, respectively. The characteristics of men were similar to those of women.

\section{Associations of low-carbohydrate diets with CVD and total mortality}

The results of Cox analyses on the associations of usual LCD with CVD and total mortality in women and in women and men combined are given in Table 3. The usual LCD score for women was significantly inversely associated with CVD mortality in age-adjusted model $1\left(P_{\text {trend }}=0.030\right)$. Adjustments for confounding risk factors in women resulted in a more significant trend in model $2\left(P_{\text {trend }}=0.024\right)$. Further adjustments for possible mediators, serum glucose and blood sugar, and a confounder, serum creatinine, resulted in a lower $P_{\text {trend }}$ value in model 3 (HR in decile $10=0.59$, $95 \%$ CI $0.38,0.92$, HR per decile $\left.=0.97, P_{\text {trend }}=0.019\right)$. Finally, with further adjustment for total fibre intake, Na:K ratio and employee class included in model 4, the inverse association remained significant (HR in decile $10=0.60$, $95 \%$ CI $0.38,0.94$, HR per decile $\left.=0.97, P_{\text {trend }}=0.021\right)$. In model 3 analysis in women and men combined with adjustment for sex also, a significant inverse association with CVD mortality was observed (HR in decile 10=0.74, 95\% CI $0.55,0.99$, HR per decile $=0.98, P_{\text {trend }}=0.033$ ). In model 4 analysis in women and men combined, the inverse association with CVD mortality was attenuated (HR in decile $10=0.78$, $95 \%$ CI $0.458,1.05$, HR per decile $=0.98, P_{\text {trend }}=0.079$ ).

During follow-up for 14 and 19 years, 242 and 355 CVD deaths, respectively, in women were confirmed. In model 4 analyses at 14 years of follow-up, the inverse association of usual LCD score with CVD mortality was not significant (HR per decile $\left.=0.96, P_{\text {trend }}=0 \cdot 127\right)$, but it was statistically significant at 19 years of follow-up (HR per decile $=0.96$, $\left.P_{\text {trend }}=0.024\right)$.

The animal-based LCD score for women was significantly inversely associated with CVD mortality in models 2 and 3 $\left(P_{\text {trend }}=0.046\right.$ and 0.028), but not in model 1 $\left(P_{\text {trend }}=0.064\right)$. In model 4 analysis in women, the inverse association with CVD mortality remained significant (HR in decile $10=0.73,95 \%$ CI $0.48,1 \cdot 10$, HR per decile $=0.97$, $P_{\text {trend }}=0.038$ ). In model 3 analysis in women and men combined with adjustment for sex also, a significant inverse association with CVD mortality was observed (HR in decile $10=0.79, \quad 95 \% \quad$ CI $0.60, \quad 1.05, \quad$ HR per decile $=0.98$, $P_{\text {trend }}=0.046$ ). In model 4 analysis in women and men combined, the inverse association with CVD mortality was attenuated (HR in decile $10=0.83,95 \%$ CI $0.63,1 \cdot 11$, HR per decile $\left.=0 \cdot 98, P_{\text {trend }}=0 \cdot 140\right)$ (Table S1, available online).

The plant-fish-based LCD score for women was marginally inversely associated with CVD mortality in models $1-3$ $\left(P_{\text {trend }}=0.051,0.050,0 \cdot 050\right)$. In model 4 analysis in women, the inverse association became significant (HR in decile $10=0.73, \quad 95 \%$ CI $0.49, \quad 1.09, \quad$ HR per decile $=0.97$, $\left.P_{\text {trend }}=0.046\right)$. In model 3 analysis in women and men combined with adjustment for sex, a significant inverse association with CVD mortality was observed (HR in decile $10=0.83$, $95 \%$ CI $0.63,1.08$, HR per decile $\left.=0.98, P_{\text {trend }}=0.016\right)$. In model 4 analysis in women and men combined, the inverse association with CVD mortality remained significant (HR in decile $10=0.84,95 \%$ CI $0.64,1 \cdot 11$, HR per decile $=0.98$, $\left.P_{\text {trend }}=0.026\right)$ (Table S1, available online)

The usual LCD score for women was significantly inversely associated with total mortality in age-adjusted model 1 ( $P_{\text {trend }}=0.018$. Adjustments for confounding risk factors in women resulted in a more significant trend in model 2 $\left(P_{\text {trend }}=0.016\right)$. Further adjustments for possible mediators, serum glucose and blood sugar, and a confounder, serum creatinine, resulted in a lower $P_{\text {trend }}$ value in model 3 
Table 2. Characteristics of participants in 1980 according to the low-carbohydrate diet (LCD) score for women - NIPPON DATA80, 1980-2009 (Mean values with their standard errorst; mean values and standard deviations; medians and ranges; number of participants and percentages)

\begin{tabular}{|c|c|c|c|c|c|c|c|c|c|c|c|c|c|c|c|c|c|c|}
\hline & \multicolumn{6}{|c|}{ Usual LCD } & \multicolumn{6}{|c|}{ Animal-based LCD } & \multicolumn{6}{|c|}{ Plant-fish-based LCD } \\
\hline & \multicolumn{2}{|c|}{ Decile 1} & \multicolumn{2}{|c|}{ Decile 5} & \multicolumn{2}{|c|}{ Decile 10} & \multicolumn{2}{|c|}{ Decile 1} & \multicolumn{2}{|c|}{ Decile 5} & \multicolumn{2}{|c|}{ Decile 10} & \multicolumn{2}{|c|}{ Decile 1} & \multicolumn{2}{|c|}{ Decile 5} & \multicolumn{2}{|c|}{ Decile 10} \\
\hline & Mean & $\mathrm{SE}$ & Mean & SE & Mean & SE & Mean & SE & Mean & SE & Mean & $\mathrm{SE}$ & Mean & SE & Mean & SE & Mean & SE \\
\hline$n$ & \multicolumn{2}{|c|}{483} & \multicolumn{2}{|c|}{634} & \multicolumn{2}{|l|}{436} & \multicolumn{2}{|c|}{485} & \multicolumn{2}{|c|}{432} & \multicolumn{2}{|c|}{579} & \multicolumn{2}{|c|}{594} & \multicolumn{2}{|c|}{307} & \multicolumn{2}{|l|}{439} \\
\hline LCD score & & & & & & & & & & & & & & & & & & \\
\hline Median & 3 & & 14 & & 27 & & 3 & & 14 & & 27 & & 7 & & 14 & & 25 & \\
\hline Range & $0-$ & & $13-1$ & & $20-3$ & & $0-$ & & $13-1$ & & $26-3$ & & $1-\varepsilon$ & & $14-1$ & & $23-3 c$ & \\
\hline Ageł (years) & & & & & & & & & & & & & & & & & & \\
\hline Mean & 57 & & 50.0 & & $47 \cdot 7^{*}$ & & 59 & & $50.8^{*}$ & & $45 \cdot 5^{*}-x-5$ & & $57 \cdot$ & & $49 \cdot 7^{*}$ & & $50 \cdot 3^{*}$ & \\
\hline SD & 13. & & 13 & & 11.9 & & 12 & & $13 \cdot 1$ & & 11.5 & & 14. & & 11.9 & & 11.9 & \\
\hline BMI (kg/m²) & 23.0 & 0.2 & 23.0 & 0.1 & 22.9 & 0.2 & 23.1 & 0.2 & 23.1 & 0.2 & 22.7 & 0.1 & 22.7 & 0.1 & 22.9 & 0.2 & 23.0 & 0.2 \\
\hline Crude prevalence (\%) & & & & & & & & & & & & & & & & & & \\
\hline Hypertension & 51. & & 39.6 & & 34.4 & & 55 & & 43.5 & & 30.2 & & 51. & & 43.0 & & $38 \cdot 7$ & \\
\hline Current smoker & 7.9 & & 8.4 & & $10 \cdot 3$ & & 6. & & 8.8 & & $12 \cdot 1^{*}$ & & 8.9 & & 8.8 & & 7.5 & \\
\hline Current drinker & 12. & & 20. & & $24.5^{*}$ & & 11. & & $21 \cdot 1$ & & $26 \cdot 9^{*}$ & & 17 & & 21.8 & & $21 \cdot 0$ & \\
\hline Executive & 0.6 & & $1 \cdot 1$ & & $2 \cdot 1$ & & 0. & & 0.5 & & $1.9^{*}$ & & 0.7 & & 0.3 & & 0.5 & \\
\hline Professional & $6 \cdot 0$ & & 9.9 & & $14.7^{\star}$ & & 4. & & $14 \cdot 1$ & & $15 \cdot 5^{*}$ & & 6.9 & & $12 \cdot 7$ & & $13 \cdot 9^{*}$ & \\
\hline $\mathrm{TCH}(\mathrm{mmol} / \mathrm{l})$ & 4.84 & 0.04 & 4.87 & 0.03 & $5.08^{* *}$ & 0.04 & 4.74 & 0.04 & $4.92^{\star \star}$ & 0.04 & $5 \cdot 08^{\star \star}$ & 0.04 & 4.87 & 0.04 & 4.91 & 0.05 & $5 \cdot 10^{* *}$ & 0.04 \\
\hline Blood glucose (mmol/l) & 5.62 & 0.07 & 5.47 & 0.06 & 5.54 & 0.08 & 5.64 & 0.07 & 5.50 & 0.08 & 5.53 & 0.07 & 5.58 & 0.07 & 5.41 & 0.09 & 5.59 & 0.07 \\
\hline Energy (kJ/d) & 8195 & 75 & 8076 & 67 & 7955 & 80 & 8014 & 75 & 8156 & 80 & 7905 & 71 & 8428 & 71 & $7988^{\star \star}$ & 92 & $7930^{\star \star}$ & 80 \\
\hline Rice (g/d) & 286.8 & 2.8 & $214 \cdot 4^{\star \star}$ & 2.4 & $141 \cdot 3^{\star \star}$ & 2.9 & 284.4 & $2 \cdot 8$ & $217 \cdot 6^{\star \star}$ & 2.9 & $142 \cdot 2^{\star \star}$ & 2.6 & $271 \cdot 6$ & $2 \cdot 7$ & $211 \cdot 7^{\star \star}$ & 3.7 & $160 \cdot 0^{\star \star}$ & 3.1 \\
\hline Flour product (g/d) & 75.5 & $2 \cdot 3$ & 81.5 & $2 \cdot 0$ & $84.7^{\star}$ & $2 \cdot 4$ & 69.5 & $2 \cdot 3$ & $82 \cdot 5^{\star \star}$ & 2.4 & $89 \cdot 9^{\star \star}$ & $2 \cdot 1$ & 71.9 & $2 \cdot 1$ & $79 \cdot 8^{* \star}$ & $2 \cdot 8$ & $91 \cdot 8^{\star \star}$ & 2.4 \\
\hline Fruits (g/d) & 172.0 & 5.8 & 184.0 & $5 \cdot 0$ & $197 \cdot 6^{*}$ & $6 \cdot 1$ & 166.0 & 5.8 & $199 \cdot 6^{\star \star}$ & $6 \cdot 1$ & $186 \cdot 2$ & $5 \cdot 3$ & $201 \cdot 1$ & $5 \cdot 3$ & $186 \cdot 9$ & $7 \cdot 2$ & $184 \cdot 7$ & 6.0 \\
\hline $\begin{array}{l}\text { Green and yellow } \\
\text { vegetables ( } \mathrm{g} / \mathrm{d})\end{array}$ & $48 \cdot 3$ & 1.9 & $56 \cdot 3^{\star \star}$ & 1.6 & $72 \cdot 8^{\star \star}$ & 1.9 & $49 \cdot 8$ & 1.9 & $56 \cdot 3$ & $2 \cdot 0$ & $67 \cdot 0^{\star \star}$ & 1.7 & $41 \cdot 3$ & 1.7 & $53.0^{* \star}$ & $2 \cdot 3$ & $77 \cdot 8^{\star *}$ & 1.9 \\
\hline Fish and shellfish (g/d) & 68.5 & $2 \cdot 2$ & $98 \cdot 7^{\star \star}$ & 1.9 & $120 \cdot 3^{\star \star}$ & $2 \cdot 3$ & 65.9 & $2 \cdot 2$ & $100 \cdot 7^{\star \star}$ & $2 \cdot 3$ & $115 \cdot 1^{\star \star}$ & $2 \cdot 0$ & $98 \cdot 1$ & $2 \cdot 0$ & 96.9 & 2.8 & $97 \cdot 9$ & $2 \cdot 3$ \\
\hline Meats (g/d) & 29.8 & 1.4 & $48 \cdot 6^{\star \star}$ & $1 \cdot 2$ & $86 \cdot 9^{* *}$ & 1.4 & $26 \cdot 1$ & 1.3 & $46 \cdot 8^{\star \star}$ & 1.4 & $89 \cdot 1^{\star \star}$ & $1 \cdot 2$ & 41.9 & 1.3 & $51 \cdot 7^{\star \star}$ & 1.8 & $61 \cdot 4^{\star \star}$ & 1.5 \\
\hline Eggs (g/d) & $25 \cdot 3$ & 0.8 & $33 \cdot 3^{\star \star}$ & 0.7 & $47 \cdot 1^{* *}$ & 0.9 & 23.5 & 0.8 & $34 \cdot 1^{\star \star}$ & 0.9 & $45 \cdot 8^{\star \star}$ & 0.8 & 30.5 & 0.8 & $34 \cdot 4^{*}$ & 1.1 & $40 \cdot 7^{* *}$ & 0.9 \\
\hline Total fibre $(\mathrm{g} / 4189 \mathrm{~kJ})$ & 8.7 & 0.1 & $9 \cdot 3^{\star *}$ & 0.1 & $9 \cdot 5^{\star \star}$ & 0.1 & $9 \cdot 3$ & 0.1 & 9.4 & 0.1 & 9.0 & 0.1 & 8.2 & 0.1 & $9 \cdot 3^{\star \star}$ & 0.1 & $10 \cdot 4^{\star \star}$ & 0.1 \\
\hline $\mathrm{Na}(\mathrm{mg} / 4186 \mathrm{~kJ})$ & 2434 & 39 & $2681^{\star \star}$ & 34 & $2848^{\star *}$ & 41 & 2712 & 40 & 2717 & 41 & 2679 & 36 & 2266 & 35 & $2734^{\star \star}$ & 48 & $3081^{\star \star}$ & 40 \\
\hline $\mathrm{K}(\mathrm{mg} / 4186 \mathrm{~kJ})$ & 1275 & 12 & $1436^{\star \star}$ & 10 & $1632^{\star *}$ & 12 & 1325 & 12 & $1451^{\star \star}$ & 12 & $1573^{\star \star}$ & 11 & 1298 & 11 & $1458^{\star \star}$ & 15 & $1607^{\star \star}$ & 12 \\
\hline Carbohydrate (\%kJ) & $72 \cdot 7$ & 0.1 & $63 \cdot 2^{\star \star}$ & 0.1 & $51 \cdot 5^{* *}$ & 0.1 & $72 \cdot 8$ & 0.2 & $63 \cdot 5^{\star \star}$ & 0.2 & $52 \cdot 6^{\star \star}$ & 0.1 & $69 \cdot 3$ & 0.2 & $63 \cdot 1^{* \star}$ & 0.2 & $55 \cdot 4^{* \star}$ & 0.2 \\
\hline Protein (\%kJ) & 12.9 & 0.1 & $15 \cdot 4^{\star \star}$ & 0.1 & $18 \cdot 3^{* \star}$ & 0.1 & $13 \cdot 2$ & 0.1 & $15 \cdot 4^{\star \star}$ & 0.1 & $17 \cdot 8^{\star \star}$ & 0.1 & 14.1 & 0.1 & $15 \cdot 5^{* \star}$ & 0.1 & $17 \cdot 1^{\star \star}$ & 0.1 \\
\hline Animal protein (\%kJ) & 5.5 & 0.1 & $8 \cdot 6^{\star *}$ & 0.1 & $12 \cdot 5^{\star \star}$ & 0.1 & $5 \cdot 1$ & 0.1 & $8 \cdot 6^{\star \star}$ & 0.1 & $12 \cdot 6^{\star \star}$ & 0.1 & 7.8 & 0.1 & $8 \cdot 8^{\star \star}$ & 0.1 & $9 \cdot 7^{\star *}$ & 0.1 \\
\hline Vegetable protein (\%kJ) & 8.0 & 0.0 & $7 \cdot 6^{\star \star}$ & 0.0 & $7 \cdot 0^{\star \star}$ & 0.0 & 8.4 & 0.0 & $7 \cdot 6^{\star \star}$ & 0.0 & $6 \cdot 7^{\star \star}$ & 0.0 & $7 \cdot 1$ & 0.0 & $7 \cdot 6^{\star \star}$ & 0.1 & $8 \cdot 3^{\star \star}$ & 0.0 \\
\hline Total fat (\%kJ) & 14.1 & 0.2 & $20 \cdot 6^{\star *}$ & 0.1 & $29 \cdot 4^{\star \star}$ & 0.2 & $14 \cdot 1$ & 0.2 & $20.5^{\star \star}$ & 0.2 & $28 \cdot 6^{\star \star}$ & 0.2 & 16.0 & 0.2 & $20 \cdot 4^{* *}$ & 0.2 & $27 \cdot 1^{* *}$ & 0.2 \\
\hline Saturated fat (\%kJ) & 4.3 & 0.0 & $5 \cdot 9^{\star \star}$ & 0.0 & $8 \cdot 1^{\star \star}$ & 0.1 & 4.0 & 0.0 & $5 \cdot 8^{\star \star}$ & 0.0 & $8 \cdot 5^{\star \star}$ & 0.0 & $5 \cdot 1$ & 0.1 & $5 \cdot 9^{\star \star}$ & 0.1 & $7 \cdot 1^{\star \star}$ & 0.1 \\
\hline MUFA + PUFA (\%kJ) & 9.5 & 0.1 & $13 \cdot 3^{\star \star}$ & 0.1 & $18 \cdot 2^{2 *}$ & 0.1 & 9.6 & 0.1 & $13 \cdot 3^{\star \star}$ & 0.1 & $17 \cdot 5^{\star \star}$ & 0.1 & $10 \cdot 0$ & 0.1 & $12 \cdot 9^{* *}$ & 0.1 & $17 \cdot 9^{\star \star}$ & 0.1 \\
\hline
\end{tabular}

$\mathrm{TCH}$, total cholesterol.

Mean values were significantly different from those of the decile 1 group: ${ }^{*} P<0.05 ;{ }^{* \star} P<0.01$. A one-way ANOVA was used to compare means among the groups, followed by a post hoc Dunnett's test, taking decile 1 as a

reference, when there was a significant difference in $F$ value $(P<0.05)$.
+ Continuous variables, except age, are age-adjusted data by ANCOVA.

$\ddagger$ The $\chi^{2}$ test was used to compare dichotomous variables, followed by a post hoc logistic analysis adjusted for age. 
Table 3. CVD and total mortality in women and in women and men combined according to the usual low-carbohydrate diet score (Hazard ratios $(\mathrm{HR})^{\star}$ and $95 \%$ confidence intervals; number of cases and ranges)

\begin{tabular}{|c|c|c|c|c|c|c|c|c|c|c|c|c|c|c|c|c|c|c|c|c|c|}
\hline & \multirow[b]{2}{*}{ Decile 1} & \multicolumn{2}{|c|}{ Decile 2} & \multicolumn{2}{|c|}{ Decile 3} & \multicolumn{2}{|c|}{ Decile 4} & \multicolumn{2}{|c|}{ Decile 5} & \multicolumn{2}{|c|}{ Decile 6} & \multicolumn{2}{|c|}{ Decile 7} & \multicolumn{2}{|c|}{ Decile 8} & \multicolumn{2}{|c|}{ Decile 9} & \multicolumn{2}{|c|}{ Decile 10} & \multirow[b]{2}{*}{$\mathrm{HR}$} & \multirow{2}{*}{$\begin{array}{l}\text { Decile } \\
\text { trend } P\end{array}$} \\
\hline & & $\mathrm{HR}$ & $95 \% \mathrm{Cl}$ & $\mathrm{HR}$ & $95 \% \mathrm{Cl}$ & $\mathrm{HR}$ & $95 \% \mathrm{Cl}$ & $\mathrm{HR}$ & $95 \% \mathrm{Cl}$ & $\mathrm{HR}$ & $95 \% \mathrm{Cl}$ & $\mathrm{HR}$ & $95 \% \mathrm{Cl}$ & $\mathrm{HR}$ & $95 \% \mathrm{Cl}$ & $\mathrm{HR}$ & $95 \% \mathrm{Cl}$ & $\mathrm{HR}$ & $95 \% \mathrm{Cl}$ & & \\
\hline \multicolumn{22}{|l|}{ CVD mortality } \\
\hline & 92 & \multirow{2}{*}{\multicolumn{2}{|c|}{$\begin{array}{c}86 \\
10878\end{array}$}} & \multirow{2}{*}{\multicolumn{2}{|c|}{$\begin{array}{c}101 \\
14621\end{array}$}} & \multirow{2}{*}{\multicolumn{4}{|c|}{$\begin{array}{c}66 \\
16092\end{array}$}} & \multirow{2}{*}{\multicolumn{2}{|c|}{$\begin{array}{c}51 \\
12077\end{array}$}} & \multirow{2}{*}{\multicolumn{4}{|c|}{$\begin{array}{c}40 \\
16748\end{array}$}} & \multirow{2}{*}{\multicolumn{2}{|c|}{$\begin{array}{c}43 \\
13865\end{array}$}} & \multicolumn{2}{|c|}{$\begin{array}{c}25 \\
11657\end{array}$} & & \\
\hline Person-years & 11112 & & & & & & & \multirow{2}{*}{\multicolumn{2}{|c|}{$\begin{array}{l}16092 \\
13-15\end{array}$}} & & & & & & & & 13865 & & 1657 & & \\
\hline Score range & $0-4$ & \multicolumn{2}{|r|}{$5-7$} & \multicolumn{2}{|r|}{$\begin{array}{l}14627 \\
8-10\end{array}$} & \multicolumn{2}{|c|}{$\begin{array}{l}71314 \\
11-12\end{array}$} & & $13-15$ & \multicolumn{2}{|c|}{$16-17$} & \multicolumn{2}{|c|}{$18-19$} & & $20-22$ & & $23-25$ & & $6-30$ & & \\
\hline Model $1 \dagger$ & 1.00 & 1.04 & $0.78,1.40$ & 1.01 & $0.76,1.34$ & 0.90 & $0.65,1 \cdot 25$ & 0.95 & $0.69,1.31$ & 0.97 & $0.69,1.37$ & 1.15 & $0.82,1.63$ & 0.73 & $0.50,1.06$ & 0.94 & $0.65,1.35$ & 0.58 & $0.37,0.90$ & 0.97 & 0.030 \\
\hline Model 2ł & 1.00 & 1.00 & $0.75,1 \cdot 35$ & 0.98 & $0.74,1.31$ & 0.87 & $0.62,1.20$ & 0.92 & $0.67,1.26$ & 0.95 & $0.68,1.35$ & 1.11 & $0.79,1.58$ & 0.71 & $0.49,1.03$ & 0.90 & $0.63,1 \cdot 30$ & 0.56 & $0.36,0.88$ & 0.97 & 0.024 \\
\hline Model $3 \S$ & 1.00 & 1.02 & $0.76,1.38$ & 0.99 & $0.74,1.31$ & & $0.64,1.23$ & 0.93 & $0.67,1.27$ & 0.92 & $0.65,1.30$ & 1.15 & $0.81,1.63$ & 0.70 & $0.48,1.02$ & 0.87 & $0.60,1 \cdot 25$ & 0.59 & $0.38,0.92$ & 0.97 & 0.019 \\
\hline Model 4\| & 1.00 & 1.02 & $0.76,1.37$ & 1.00 & $0.75,1.33$ & 0.90 & $0.64,1.24$ & 0.93 & $0.67,1.28$ & 0.92 & $0.65,1.31$ & 1.14 & $0.81,1.62$ & 0.70 & $0.48,1.02$ & 0.86 & $0.60,1 \cdot 26$ & 0.60 & $0.38,0.94$ & 0.97 & 0.021 \\
\hline Men + women & & & & & & & & & & & & & & & & & & & & & \\
\hline$n$ & 166 & & 158 & & 194 & & 100 & & 136 & & 86 & & 87 & & 91 & & 91 & & 62 & & \\
\hline Person-years & 18993 & & 18433 & & 25554 & & 19620 & & 28266 & & 20563 & & 9658 & & 9606 & & 23625 & & 20293 & & \\
\hline Model 3ף & 1.00 & 1.09 & $0.87,1 \cdot 35$ & 1.04 & $0.85,1 \cdot 28$ & 0.87 & $0.68,1 \cdot 11$ & 0.98 & $0.78,1 \cdot 24$ & 0.89 & $0 \cdot 68,1 \cdot 16$ & 1.06 & $0.82,1 \cdot 38$ & 0.80 & $0.61,1.03$ & 1.02 & $0 \cdot 79,1 \cdot 32$ & 0.74 & $0.55,0.99$ & 0.98 & 0.033 \\
\hline Model 4ף & 1.00 & 1.09 & $0.87,1.36$ & 1.06 & $0.86,1 \cdot 30$ & 0.87 & $0.68,1 \cdot 12$ & 1.00 & $0.79,1.25$ & 0.91 & $0 \cdot 70,1 \cdot 18$ & 1.08 & $0.83,1.40$ & 0.82 & $0.63,1.06$ & 1.05 & $0.81,1 \cdot 36$ & 0.78 & $0.58,1.05$ & 0.98 & 0.079 \\
\hline Total mortality & & & & & & & & & & & & & & & & & & & & & \\
\hline & 233 & & 211 & & 253 & & 156 & & 191 & & 137 & & 123 & & 129 & & 127 & & 86 & & \\
\hline Model $1 \dagger$ & 1.00 & 1.02 & $0.84,1.22$ & 1.00 & $0.84,1.19$ & 0.91 & $0.74,1.12$ & 1.02 & $0.84,1.23$ & 0.95 & $0.77,1.17$ & 1.01 & $0.81,1.26$ & 0.83 & $0.67,1.04$ & 0.97 & $0.78,1.21$ & 0.71 & $0.56,0.91$ & 0.98 & 0.018 \\
\hline Model 2f & 1.00 & 1.00 & $0.83,1.21$ & 0.98 & $0.82,1.18$ & 0.90 & $0.73,1 \cdot 10$ & 1.01 & $0.83,1 \cdot 22$ & 0.94 & $0.76,1 \cdot 16$ & 1.00 & $0.80,1 \cdot 24$ & 0.83 & $0.66,1.03$ & 0.96 & $0.77,1.20$ & 0.70 & $0.55,0.90$ & 0.98 & 0.016 \\
\hline Model $3 \S$ & 1.00 & 1.01 & $0.84,1 \cdot 22$ & 0.99 & $0.83,1 \cdot 18$ & 0.92 & $0.75,1.13$ & 1.02 & $0.84,1 \cdot 23$ & 0.93 & $0.75,1 \cdot 15$ & 1.03 & $0.82,1 \cdot 28$ & 0.83 & $0.67,1.04$ & 0.95 & $0.76,1 \cdot 18$ & 0.73 & $0.57,0.93$ & 0.98 & 0.020 \\
\hline Model 4\| & 1.00 & 1.01 & $0.84,1 \cdot 22$ & 0.99 & $0.83,1.19$ & 0.92 & $0.75,1 \cdot 13$ & 1.02 & $0.84,1 \cdot 24$ & 0.94 & $0.76,1 \cdot 16$ & 1.03 & $0.82,1 \cdot 28$ & 0.84 & $0.67,1.04$ & 0.96 & $0.77,1 \cdot 20$ & 0.74 & $0.57,0.95$ & 0.98 & 0.029 \\
\hline Men + women & & & & & & & & & & & & & & & & & & & & & \\
\hline$n$ & 466 & & 423 & & 507 & & 310 & & 407 & & 270 & & 249 & & 310 & & 281 & & 220 & & \\
\hline Model 3ף & 1.00 & 1.04 & $0.91,1 \cdot 19$ & 0.96 & $0.84,1.08$ & 0.94 & $0.82,1.09$ & 0.98 & $0.85,1.12$ & 0.92 & $0.79,1.07$ & 0.97 & $0.83,1.14$ & 0.87 & $0.75,1.00$ & 1.00 & $0.86,1 \cdot 16$ & 0.84 & $0.72,0.99$ & 0.99 & 0.030 \\
\hline Model 4" & 1.00 & 1.04 & $0.91,1.19$ & 0.97 & $0.85,1 \cdot 10$ & 0.95 & $0.82,1 \cdot 10$ & 0.98 & $0.86,1 \cdot 13$ & 0.93 & $0.80,1.09$ & 0.99 & $0.85,1 \cdot 16$ & 0.88 & $0.76,1.02$ & 1.02 & $0.88,1 \cdot 20$ & 0.87 & $0.74,1.02$ & 0.99 & 0.090 \\
\hline
\end{tabular}

* We calculated HR using a Cox proportional-hazards model.

† Variables in model 1 were age and deciles of diet scores. 1 variables and BMI (five categories divided at $18.5,23,25$ and $30 \mathrm{~kg} / \mathrm{m}^{2} ; 18.5-23 \mathrm{~kg} / \mathrm{m}^{2}$ : a reference), hypertension, cigarette smoking (never-smokers, ex-smokers, and three categories of current smokers divided at twenty and forty cigarettes per d; never-smokers: a reference) and alcohol consumption (ex-drinkers, current drinkers, and never-drinkers; never-drinkers: a reference).

$\S$ Model 2 variables and serum total cholesterol and blood glucose concentrations (standardised to have the mean at 0 (SD 1)) and serum creatinine concentrations (divided at the 75 th percentile, $10 \mathrm{mg} /$ ).

$\|$ Model 3 variables and total dietary fibre intake, Na:K ratio and employee classes (executive, professional and others; others: a reference).

II Model 3 and 4 in women and men combined: model 3 and 4 variables and sex. 
(HR in decile $10=0.73,95 \%$ CI $0.57,0.93$, HR per decile $\left.=0.98, P_{\text {trend }}=0.020\right)$. In model 4 analysis in women, the inverse association remained significant (HR in decile $10=0.74, \quad 95 \%$ CI $0.57, \quad 0.95, \quad$ HR per decile $=0.98$, $P_{\text {trend }}=0.029$ ). In model 3 analysis in women and men combined with adjustment for sex also, a significant inverse association with total mortality was observed (HR in decile $10=0.84,95 \%$ CI $\left.0.72,0.99, P_{\text {trend }}=0.030\right)$. However, in model 4 analysis in women and men combined, the inverse association with total mortality was attenuated (HR in decile $10=0.87, \quad 95 \%$ CI $0.74, \quad 1.02, \quad$ HR per decile $=0.99$, $\left.P_{\text {trend }}=0 \cdot 090\right)($ Table 3 ).

The results of Cox analyses on the associations of LCD with CVD and total mortality in men are given in Table S4 (available online). Although all the three types of LCD tended to be inversely associated with CVD or total mortality, none of the associations was statistically significant.

\section{Discussion}

We found that a usual LCD was significantly inversely associated with CVD and total mortality in women and in women and men combined, independent of confounders in our large cohort. We did not observe any differential effects of animal-based and plant-based LCD. Inclusion of total fibre intake, Na:K ratio and employee class, a marker of socio-economic status (SES), in models resulted in the attenuation of statistical significance in some, but not in all, analyses.

This is the first long-term study to show a beneficial effect of a moderate usual LCD on CVD and total mortality. Despite several studies showing that LCD are effective at promoting weight loss and inducing a better cardiovascular risk profile $\mathrm{e}^{(2-5)}$, previous long-term studies in people mostly living in Western countries have shown either neutral or adverse effects of LCD on total mortality, CVD morbidity and/or mortality ${ }^{(7-10)}$. A recent meta-analysis carried out by Noto et al. ${ }^{(12)}$ has found that LCD are associated with a significantly higher risk of total mortality without any changes in CVD morbidity or mortality. Fung et al. ${ }^{(7)}$ showed the animal-based LCD score to be associated with higher CVD and total mortality and cancer mortality in the Nurses' Health Study and Health Professionals Follow-up Study. In contrast, Fung et al. ${ }^{(7)}$ also showed a higher vegetable-based LCD score to be associated with lower CVD and total mortality. Lagiou et al. ${ }^{(9)}$ followed up 43396 middle-aged participants in Sweden and found LCD to be associated with an increased risk of CVD.

Exploring the reasons for differences in the results of the present study and those of previous studies carried out in Western countries is of interest. Compared with Western populations, Japanese people living in Japan consume a higher amount of carbohydrate. For both women and men, about $60 \%$ of energy was from carbohydrate, which was about 10 points higher than that reported in previous studies in Western populations ${ }^{(6,16,23)}$. In the present study, even for women in the lowest stratum of carbohydrate intake, the intake values ranged from $17 \cdot 3$ to $53.5 \%$, and for men, the values ranged from 18.8 to $51.6 \%$. Even for women and men in decile 10 of LCD score, the mean carbohydrate intake was about $50 \%$ of total energy. Because very few participants were obese and mean BMI was not different across the deciles of LCD score, they appeared to have not followed strict carbohydrate restrictions as recommended by Atkins $^{(24)}$. In fact, this diet was not known in 1980 in Japan. For women and men in the higher-LCD score groups of all the three LCD types, age-adjusted intakes of fruits, vegetables, fish and shellfish, meats, and eggs were higher. It is understandable that the former three dietary tendencies resulted in better cardiometabolic risk profiles and outcomes judging from the results of previous studies ${ }^{(25,26)}$. However, the latter two dietary tendencies could have resulted in worse cardiometabolic risk profiles and outcomes as reported in previous studies $^{(27,28)}$.

A large-scale INTERMAP study has shown that dietary animal protein intake is not associated with higher BP after adjustment for height and weight, while vegetable protein intake is inversely associated with $\mathrm{BP}^{(29)}$. Interestingly, several longitudinal studies have suggested a beneficial effect of meat intake on cardiovascular outcomes. Using the Hiroshima/ Nagasaki Life Span Study cohort data, Sauvaget et al. ${ }^{(30,31)}$ showed that the intake of animal products has protective effects against intracerebral haemorrhage and cerebral infarction. A pooled analysis of Asian prospective cohort studies has shown that red meat intake is inversely associated with CVD mortality in men ${ }^{(32)}$. Recently, the intake of animal protein and fat has increased significantly in Japan; however, the current mean intake of these nutrients in Japan is still low compared with that in Western countries ${ }^{(33,34)}$. It is possible that even if a very high meat intake is associated with negative outcomes, a higher intake in a lower range may have beneficial effects.

In the present study, we did not observe any differential effects of animal-based and plant-based LCD that have been indicated in studies carried out mostly in the USA. In a study carried out in Sweden, Lagiou et al. ${ }^{(9)}$ also failed to find such differential effects. This may have resulted from the above-mentioned reasons.

Although all the three types of LCD tended to be inversely associated with CVD or total mortality, none of the associations was statistically significant in men, unlike in women. Variability in dietary estimates caused by chance eating out may have been higher in men than in women because the proportion of men in full-time employment was higher than that of women; a higher prevalence of current smoking and alcohol drinking in men than in women resulted in some dilution of the effects of LCD on CHD mortality in men.

We observed an influence of SES on LCD scores: percentages of participants with a higher SES were higher in the higher-LCD score groups. A higher intake of protein and a lower intake of carbohydrates in participants in higher-SES groups have been shown in a previous study ${ }^{(35)}$. However, inclusion of total dietary fibre intake, Na:K ratio and employee class, a marker of SES, in models in the present study resulted in the attenuation of statistical significance in some, but in not all, the analyses.

We recruited a large cohort of participants from randomly selected health districts in Japan. The participants of the 
present study were followed up for 29 years, which is a long period, and this increases the value of the present study.

\section{Study limitations}

The present study has several limitations. First, the follow-up period was long and dietary exposure may have changed over time ${ }^{(35)}$. To avoid misclassification of dietary exposure over time, repeated dietary intake assessments would have been better. However, this possible variability generally tends to result in underestimated risk. The results of model 4 analyses of usual LCD score for CVD mortality in women at 14 and 19 years, in addition to 29 years, of follow-up did not indicate any significant dilution of effects over long follow-up duration. Second, information on fish oil supplementation was not available in the baseline surveys, although supplement use was not common among Japanese in 1980. Third, residual confounding from unmeasured or unknown factors cannot be excluded. For example, physical activity and amount of alcohol consumption (although we used values of alcohol consumption frequency) were not considered in the present study. Lastly, data on CVD incidence were not available; therefore, we could not examine the relationships with CVD incidence.

\section{Conclusions}

Moderate diets lower in carbohydrate and higher in protein and fat are significantly inversely associated with CVD and total mortality in women.

\section{Supplementary material}

To view supplementary material for this article, please visit http://dx.doi.org/10.1017/S0007114514001627

\section{Acknowledgements}

The authors thank all members of Japanese Association of Public Health Center Directors and all staff members of the public health centres that contributed to the present study. Details regarding the investigators and members of the research group are given in the appendix of Nakamura et $a .^{(18)}$.

The present study was supported in part by grants from the Ministry of Health, Labor and Welfare under the auspices of Japanese Association for Cerebro-cardiovascular Disease Control, a Research Grant for Cardiovascular Diseases (7A-2) from the Ministry of Health, Labor and Welfare, and a Health and Labor Sciences Research Grant, Japan (Comprehensive Research on Aging and Health (H11-Chouju-046, H14-Chouju-003, H17-Chouju-012， H19-Chouju-Ippan-014) and Comprehensive Research on Life-Style Related Diseases including Cardiovascular Diseases and Diabetes Mellitus (H22Jyunkankitou-Seisyu-Sitei-017, H25-Jyunkankitou-Seisyu-Sitei)).

The authors' contributions are as follows: Y. N. and H. U. designed the study; Y. N., H. U., N. O., T. O., A. K., K. M., N. M., T. H., Y. K., A. F., M. N., N. T., T. O. and A. O. conducted the study; Y. N. and H. U. analysed the data; Y. N., H. U. and K. M. wrote the article; Y. N. had primary responsibility for the final content. All authors read and approved the final manuscript.

None of the authors has any conflicts of interest to declare.

\section{References}

1. WHO (2013) Obesity and Overweight. Fact Sheet no. 311. Geneva: WHO. http://www.who.int/mediacentre/factsheets/ fs311/en/ (accessed May 2014).

2. Santos FL, Esteves SS, da Costa Pereira A, et al. (2012) Systematic review and meta-analysis of clinical trials of the effects of low carbohydrate diets on cardiovascular risk factors. Obes Rev 13, 1048-1066.

3. Krieger JW, Sitren HS, Daniels MJ, et al. (2006) Effects of variation in protein and carbohydrate intake on body mass and composition during energy restriction: a meta-regression 1 . Am J Clin Nutr 83, 260-274.

4. Hu T, Mills KT, Yao L, et al. (2012) Effects of lowcarbohydrate diets versus low-fat diets on metabolic risk factors: a meta-analysis of randomized controlled clinical trials. Am J Epidemiol 176, Suppl. 7, S44-S54.

5. Clifton PM, Condo D \& Keogh JB (2014) Long term weight maintenance after advice to consume low carbohydrate, higher protein diets - a systematic review and meta analysis. Nutr Metab Cardiovasc Dis 24, 224-235.

6. Halton TL, Willett WC, Liu S, et al. (2006) Low-carbohydratediet score and the risk of coronary heart disease in women. N Engl J Med 355, 1991-2002.

7. Fung TT, van Dam RM, Hankinson SE, et al. (2010) Low-carbohydrate diets and all-cause and cause-specific mortality: two cohort studies. Ann Intern Med 153, 289-298.

8. Sjögren P, Becker W, Warensjö E, et al. (2010) Mediterranean and carbohydrate-restricted diets and mortality among elderly men: a cohort study in Sweden. Am J Clin Nutr 92, 967-974.

9. Lagiou P, Sandin S, Lof M, et al. (2012) Low carbohydratehigh protein diet and incidence of cardiovascular diseases in Swedish women: prospective cohort study. BMJ 344, e4026.

10. Trichopoulou A, Psaltopoulou T, Orfanos P, et al. (2007) Low-carbohydrate-high-protein diet and long-term survival in a general population cohort. Eur J Clin Nutr 61, 575-581.

11. Willett WC (2007) Low-carbohydrate diets: a place in health promotion? J Intern Med 261, 363-365.

12. Noto H, Goto A, Tsujimoto T, et al. (2013) Low-carbohydrate diets and all-cause mortality: a systematic review and meta-analysis of observational studies. PLOS ONE 8, e55030.

13. Nakamura Y, Ueshima H, Okamura T, et al. (2009) A Japanese diet and 19-year mortality: national integrated project for prospective observation of non-communicable diseases and its trends in the aged, 1980. Br J Nutr 101, 1696-1705.

14. Robertson TL, Kato H, Gordon T, et al. (1977) Epidemiologic studies of coronary heart disease and stroke in Japanese men living in Japan, Hawaii and California. Coronary heart disease risk factors in Japan and Hawaii. Am J Cardiol 39, $244-249$.

15. Ueshima H, Iida M, Shimamoto T, et al. (1982) Dietary intake and serum total cholesterol level: their relationship to different lifestyles in several Japanese populations. Circulation 66, 519-526.

16. Zhou BF, Stamler J, Dennis B, et al. (2003) Nutrient intakes of middle-aged men and women in China, Japan, United 
Kingdom, and United States in the late 1990s: the INTERMAP study. J Hum Hypertens 17, 623-630.

17. Okamura T, Kadowaki T, Hayakawa T, et al. (2003) What cause of mortality can we predict by cholesterol screening in the Japanese general population? J Intern Med 253, $169-180$

18. Nakamura Y, Okamura T, Higashiyama A, et al. (2012) Prognostic values of clockwise and counter-clockwise rotation for cardiovascular mortality in Japanese (24 year follow-up of NIPPON DATA80). Circulation 125, 1226-1233.

19. Iso H, Imano H, Kitamura A, et al. (2004) Type 2 diabetes and risk of non-embolic ischaemic stroke in Japanese men and women. Diabetologia 47, 2137-2144.

20. Okuda N, Miura K, Yoshita K, et al. (2010) Integration of data from NIPPON DATA80/90 and National Nutrition Survey in Japan: for cohort studies of representative Japanese on nutrition. J Epidemiol 20, Suppl. 3, S506-S514.

21. Iwaoka F, Yoshiike N, Date C, et al. (2001) A validation study on a method to estimate nutrient intake by family members through a household-based food-weighing survey. J Nutr Sci Vitaminol (Tokyo) 47, 222-227.

22. Okamura T, Hayakawa T, Kadowaki T, et al. (2006) The inverse relationship between serum high-density lipoprotein cholesterol and all-cause mortality in a 9.6-year follow up study in the Japanese general population. Atherosclerosis 184, $143-150$.

23. ChartsBin (2010) Contribution of Carbohydrates in Total Dietary Consumption. http://chartsbin.com/view/1154 (accessed May 2014).

24. Atkins RC (1998) Dr. Atkins' New Diet Revolution, revised ed. New York, NY: Avon Books.

25. Kelemen LE, Kushi LH, Jacobs DRJ, et al. (2005) Associations of dietary protein with disease and mortality in a prospective study of postmenopausal women. Am J Epidemiol 161, $239-249$.

26. Hu FB \& Willett WC (2002) Optimal diets for prevention of coronary heart disease. JAMA 288, 2569-2578.

27. De Stefani E, Boffetta P, Ronco AL, et al. (2008) Nutrient patterns and risk of lung cancer: a factor analysis in Uruguayan men. Lung Cancer 61, 283-291.

28. Lam TK, Cross AJ, Consonni D, et al. (2009) Intakes of red meat, processed meat, and meat mutagens increase lung cancer risk. Cancer Res 69, 932-939.

29. Elliott P, Stamler J, Dyer AR, et al. (2006) Association between protein intake and blood pressure: the INTERMAP Study. Arch Int Med 166, 79-87.

30. Sauvaget C, Nagano J, Allen N, et al. (2003) Intake of animal products and stroke mortality in the Hiroshima/Nagasaki Life Span Study. Int J Epidemiol 32, 536-543.

31. Sauvaget C, Nagano J, Hayashi M, et al. (2004) Animal protein, animal fat, and cholesterol intakes and risk of cerebral infarction mortality in the adult health study. Stroke 35, 1531-1537.

32. Lee JE, McLerran DF, Rolland B, et al. (2013) Meat intake and cause-specific mortality: a pooled analysis of Asian prospective cohort studies. Am J Clin Nutr 84, 1032-1041.

33. Iso H, Stampfer MJ, Manson JE, et al. (2001) Prospective study of fat and protein intake and risk of intraparenchymal hemorrhage in women. Circulation 103, 856-863.

34. Ueshima H (1989) Changes in dietary habits, cardiovascular risk factors and mortality in Japan. Acta Cardiol $\mathbf{4 4}$, 475-477.

35. Stallone DD, Brunner EJ, Bingham SA, et al. (1997) Dietary assessment in Whitehall II: the influence of reporting bias on apparent socioeconomic variation in nutrient intakes. Eur J Clin Nutr 51, 815-825. 